\title{
Socio demographic profile of GDM using 75 gm OGCT
}

\author{
Muthuprabha P.*, Ramalakshmi S.
}

Department of Obstetrics and Gynecology, Tirunelveli Medical College Hospital, Tirunelveli, Tamil Nadu, India

Received: 04 May 2017

Revised: 13 October 2017

Accepted: 26 October 2017

\section{*Correspondence:}

Dr. Muthuprabha P.,

E-mail: drmuthuprabha85@yahoo.com

Copyright: () the author(s), publisher and licensee Medip Academy. This is an open-access article distributed under the terms of the Creative Commons Attribution Non-Commercial License, which permits unrestricted non-commercial use, distribution, and reproduction in any medium, provided the original work is properly cited.

\begin{abstract}
Background: The aim of this study was to study the prevalence of GDM in a tertiary care centre based on 75 gm OGCT and to analyse the socio demographic and clinical profile of GDM using $75 \mathrm{gm}$ OGCT in a tertiary care centre. Methods: This study was conducted in the antenatal OPD of Tirunelveli Medical College Hospital from October 2014 to July 2015, a period of 10 months on 300 antenatal women. The mothers were screened using 75gm 2-hour OGCT once during each trimester and the results analysed.

Results: The prevalence of GDM in this study was 3.4\%. Out of this 47-50\% of women with GDM were of the age group 26-30 years. $6 \%$ of the women had BMI of $>25 \mathrm{~kg} / \mathrm{m}^{2}$. The incidence of GDM was found to be high in multigravidas and $70 \%$ belonged to class V socioeconomic status. Using the 75 gm OGTT $20 \%, 40 \%$ and $40 \%$ were diagnosed during the I, II and III trimesters respectively. $90 \%$ of the women delivered at term and total caesarean section rate was $30.6 \%$. Mean birth weight of the babies was $2.9 \mathrm{~kg}$. $70 \%$ of the diagnosed GDM women were treated using Medical Nutrition Therapy (MNT).
\end{abstract}

Conclusions: $75 \mathrm{gm}$ OGCT recommended by WHO can be used to detect significant number of cases of GDM.

Keywords: 75 gm OGCT, GDM, WHO criteria

\section{INTRODUCTION}

Gestational diabetes mellitus is defined as carbohydrate intolerance of variable severity with its onset or first recognition during the present pregnancy.

According to Norman Frienkel "Fetus is a continuously feeding boarder in an intermittently eating host-mother". The metabolic adaptations during pregnancy occur in such a way as to accommodate the growing foetus.

Though diabetes mellitus is a disease known since ancient times recognition of diabetes in pregnancy is a relatively recent phenomenon. It was in 1909 that Williams described the concept of pre-existing diabetes (overt diabetes) and diabetes after conception (gestational diabetes). ${ }^{1}$
By routine screening during pregnancy an opportunity is provided for the care providers to reduce maternal and perinatal morbidity. Every woman has to be assumed to have diabetes and tests are being done to reassure her that she doesn't have it. There is an eleven-fold increased propensity in Indian women to develop glucose intolerance during pregnancy due to ethnicity.

Inspite of many screening tests available $75 \mathrm{gm} 2$ hour GCT would be ideal for a country like India where a large population needs to be screened with limited resources.

A study done in 2001 observed that the plasma glucose concentration 2 hour after administration of $75 \mathrm{~g}$ of oral glucose to a woman who has not fasted identifies the subjects with GDM. ${ }^{2}$ The adverse outcomes for the 
mother and her offspring were predicted by the nonfasting $75 \mathrm{~g}$ 2-hour post glucose concentration.

Philips et al found that the time after a meal or time of the day in a normal glucose tolerant non-pregnant woman does not affect the plasma glucose value when the glucose challenge test was performed. ${ }^{3}$

First three International workshops on GDM and ACOG in 1992 recommended screening with 50 gm oral glucose challenge test (OGCT) after which confirmation with OGTT using $100 \mathrm{gm}$ glucose is done. ADA (American Diabetes Association) suggested screening test which is $50 \mathrm{gm}$ OGCT with a cut off of $130 \mathrm{mg} / \mathrm{dl}$ and confirmation by $75 \mathrm{gm}$ or $100 \mathrm{gm} \mathrm{GTT}{ }^{4}$

In some countries over a period of seven years, at 15 centres, an International epidemiological study, Hyperglycemia and Adverse Pregnancy Outcomes (HAPO) study was conducted by using $75 \mathrm{gm}$ OGCT directly without screening in a diverse group of 23,325 antenatal women and the relationship between maternal glucose level and neonatal outcomes was observed. ${ }^{5}$ Based on this study IADPSG (International Association of Diabetes and Pregnancy Study Group) recommendations were made in $2010 .^{6}$

GDM is diagnosed by WHO criteria when the plasma glucose at 2 hours with 75 gm oral glucose is $\geq 140 \mathrm{mg} / \mathrm{dl}^{7}$

A study done in 2001 observed that the plasma glucose, 2 hours after $75 \mathrm{gm}$ oral glucose given to women who have not fasted identified the subjects with GDM and the adverse maternal and foetal outcomes were predicted by this test.

In India, Diabetes in Pregnancy Study Group India (DIPSI) recommended $75 \mathrm{gm}$ oral glucose and 2-hour plasma glucose was estimated of venous sample - a single, simple, economical and feasible test which is useful in diagnosing GDM. Balaji $\mathrm{V}$ used this test with a cut off of $\geq 140 \mathrm{mg} / \mathrm{dl}$ and evidence of GDM was found to be $16.96 \% .^{8}$ Anjalakshmi $\mathrm{C}$ et al performed this $75 \mathrm{gm}$ OGCT and compared it with 75 gm GTT and found statistically no significant difference. ${ }^{9}$

Seshiah et al in 2005 recommended this one step $75 \mathrm{gm}$ OGCT in diagnosing GDM with 2 -hour PPG $\geq 140 \mathrm{mg} / \mathrm{dl}$ as per WHO criteria. ${ }^{10}$

\section{METHODS}

300 pregnant women attending ANOPD of Tirunelveli Medical College Hospital were screened using 75 gm glucose challenge test that is 75 gm oral glucose in 300 $\mathrm{ml}$ of water is given and $2 \mathrm{hr}$ plasma glucose is estimated in venous sample irrespective of last meal. The test was done in each trimester and the mothers were followed till delivery. A cut off of $>140 \mathrm{mg} / \mathrm{dl}$ was taken. Women diagnosed as GDM were put on MNT and if not controlled on insulin. All women with no history of diabetes mellitus were included.

\section{RESULTS}

Of the total 300 screened women 10 could not be followed up so the number reduced to 290 women. The incidence of GDM was 3.4\%. Among women labelled as GDM $20.3 \%$ belonged to $26-30$ years of age group.

Table 1: Age distribution.

\begin{tabular}{|lll|l|}
\hline Age group & No GDM & GDM & Total \\
\hline 16 to 20 years & 37 & 0 & 37 \\
\hline 21 to 25 years & 159 & 1 & 160 \\
\hline 26 to 30 years & 54 & 5 & 59 \\
\hline 31 to 35 years & 30 & 3 & 33 \\
\hline 36 to 40 years & 0 & 1 & 1 \\
\hline Total & 280 & 10 & 290 \\
\hline
\end{tabular}

Among 10 GDM cases 8 (80\%)of them had their BMI $>25 \mathrm{~kg} / \mathrm{m}^{2}$ and 2 cases $(20 \%)$ were with BMI 18-25 $\mathrm{kg} / \mathrm{m}^{2}$.

Table 2: BMI range.

\begin{tabular}{|llll|}
\hline BMI range & No GDM & GDM & Total \\
\hline$<18 \mathrm{~kg} / \mathrm{m}^{2}$ & 10 & 0 & 10 \\
\hline 18 to $25 \mathrm{~kg} / \mathrm{m}^{2}$ & 250 & 2 & 252 \\
\hline$>25 \mathrm{~kg} / \mathrm{m}^{2}$ & 20 & 8 & 28 \\
\hline Total & 280 & 10 & 290 \\
\hline
\end{tabular}

Out of 10 cases $7(70 \%)$ cases belonged to class V socio economic status and $3(30 \%)$ cases belonged to class IV socioeconomic status.

Table 3: Socio economic status.

\begin{tabular}{|llll|} 
& No GDM & GDM & Total \\
\hline Class 4 & 83 & 3 & 86 \\
\hline Class 5 & 197 & 7 & 204 \\
\hline Total & 280 & 10 & 290
\end{tabular}

Out of the 10 cases $8(80 \%)$ were second gravida and above. Only 2 cases (20\%) were primi.

Table 4: Parity.

\begin{tabular}{|llll|}
\hline Parity & No GDM & GDM & Total \\
\hline Primi & 213 & 2 & 215 \\
\hline $2^{\text {nd }}$ gravida & 52 & 5 & 57 \\
\hline $3^{\text {rd }}$ gravida & 11 & 2 & 13 \\
\hline $4^{\text {th }}$ gravida & 4 & 1 & 5 \\
\hline Total & 280 & 10 & 290 \\
\hline
\end{tabular}

The total caesarean section rate was $30.6 \%$ (89 out of 290 mothers) were delivered by caesarean section. Among the GDM mothers 6 were delivered by caesarean $(60 \%)$. 
Table 5: Mode of delivery.

\begin{tabular}{|llll|}
\hline & No GDM & GDM & Total \\
\hline Labour natural & 184 & 4 & 188 \\
\hline Assisted vaginal delivery & 13 & 0 & 13 \\
\hline Caesarean & 83 & 6 & 89 \\
\hline Total & 280 & 10 & 290 \\
\hline
\end{tabular}

Mean birth weight of babies was around 2900 gms. The prevalence of macrosomia among GDM was $10 \%$. As far as management is concerned among 10 GDM mothers 7 $(70 \%)$ were put on MNT and only $3(30 \%)$ required insulin for a glycaemic control. Majority of the mothers were managed with MNT.

\section{DISCUSSION}

This study was conducted to analyze the socio demographic profile of GDM using 75 gm OGCT. It was carried out in AN OPD of Tirunelveli Medical College Hospital.

The study group comprises of 300 antenatal women. Out of this 10 mothers could not be followed and the number reduced to 290 . 75 gms OGCT was performed once in each trimester for the 290 women.

In this study the prevalence of GDM was found to be $3.4 \%$. It was also noted that with advancing age the incidence of GDM also increases with the highest prevalence of GDM in women between the age of 25 and 30 years. It was also observed that with an increase in BMI there was an increase in GDM prevalence especially when BMI was $>25 \mathrm{~kg} / \mathrm{m}^{2}$.

The prevalence was found to be more in the second gravid and low socioeconomic status that is class IV and V. Majority of GDM mothers were delivered at term by LSCS. The mean birth weight of babies was $2.9 \mathrm{~kg}$. There was no significant difference in macrosomia among mothers with GDM and without GDM.

\section{CONCLUSION}

Using 75 gm OGCT as a screening and diagnostic test the prevalence of GDM was found to be $3.4 \%$ and the incidence of GDM increases with increase in age and BMI. According to this study the prevalence of GDM was high in class IV and V Socioeconomic status. Also, there is an increased rate of caesarean section in GDM mothers. To conclude 75 gm OGCT is a single, simple, economical and feasible test which is useful in diagnosing GDM.

Funding: No funding sources

Conflict of interest: None declared

Ethical approval: The study was approved by the Institutional Ethics Committee

\section{REFERENCES}

1. Marlene M. Corton and Kenneth J. Leveno Williams obstetrics $21^{\text {st }}$ edition. 2014:1560.

2. Pettitt DJ. The $75 \mathrm{~g}$ oral glucose tolerance test in pregnancy. Diabetes Care. 2001;24:1129

3. Philips LS, Ziemer, DC, Kolm P, Weintraub WS, Vaccarino V, Rhee MK, et al. Glucose challenge test screening for prediabetes and undiagnosed diabetes. Diabetologia. 2009;52(9):1798-807.

4. American Diabetes Association. Gestational diabetes mellitus. Diabetes Care. 2004;27(1):S88-90.

5. HAPO Study Cooperative Research Group. Hyperglycemia and adverse pregnancy outcomes. N Engl J Med. 2008;358:1991-2002.

6. International association of diabetes and pregnancy study groups recommendations on the diagnosis and classification of hyperglycemia in pregnancy. Diabetes Care. 2010;33:676-82.

7. World Health Organization. Definition, diagnosis, and classification of diabetes mellitus and its complications; report of WHO consultation, Geneva: WHO document Production Services. 1999:19-20.

8. Balaji V, Madhuri BS, Ashalatha S, Sheela S, Suresh $\mathrm{S}$, Seshiah V. AIC in gestational Diabetes mellitus in Asian Indian women. Diabetes Care. 2007:30(7):1865-7.

9. Anjalakshi, C, Balaji V, Balaji MS, Ashalata S, Suganthi S, Arthi T, et al. A single test procedure to diagnose gestational diabetes mellitus. Acta Diabetol. 2009;46(1):51-4.

10. Seshiah V, Balaji V, Balaji MS, Sekar A, Sanjeevi $\mathrm{CB}$, Green A. One step procedure for screening and diagnosis of gestational diabetes mellitus. J. Obstet Gyneeol Ind. 2005;55(6):525-9.

Cite this article as: Muthuprabha $\mathrm{P}$, Ramalakshmi S. Socio demographic profile of GDM using $75 \mathrm{gm}$ OGCT. Int J Reprod Contracept Obstet Gynecol 2017;6:5327-9. 